\title{
WHY CHOOSE A SPECIFIC CAREER? WHY NOT...
}

\author{
Emil STAN, Ph.D., Mihaela SUDITU, Ph.D., \\ Educational Sciences Department, \\ Petroleum-Gas University of Ploiesti \\ estan10@yahoo.com
}

\begin{abstract}
This study analysis the way in which a post-totalitarian society (such as ours) is seeing the counselling as a profession. The paper is also approaching the reasons which are giving the options for a higher education path in an educational system in which the practice of counselling is almost absent. For this purpose we used the Holland test to observe to what measure the students from the first year from the Educational Sciences specialization.
\end{abstract}

Key words: education, Holland test, career counselling, options

\section{State of the Art}

Romanian society is a sick society. This society is sick because it has not solved the problems of the past and therefore cannot join wholeheartedly the present and especially the future. Split between the communist past and the democratic future, Romanian society today lives in confusion.

Expressing the social „disease", school witnesses the same identity crisis as shown in many reform projects which were started but not finished: it can be said that the only constant of the school in the last twenty-three years is the transition. In such a context, the implementation of counselling programs at a social scale should represent a definite imperative (almost Kantian, one would say).

It is clear that the confused situation of the Romanian society is reflected in official-public position to counselling, on the one hand, and on the other hand, in the common man's view. On a formal-institutional plan, legal regulations exist regarding the profession of psychologist, i.e. there is an association (College of Psychologists from Romania), which sets rules in the profession, which has a code of ethics (Code ofethics for the profession of psychologist) and a code of disciplinary proceedings, a methodology for accreditation of the association, etc. At the same time, there are accredited Master programs for counseling, at the Faculty of Education (accreditation comes from the Romanian Agency for Quality Assurance in Higher Education, an institution that authorizes and gives accreditation in the field 
of higher education), even though in terms of counseling, it has no legal status as a regulated profession.

At the same time, there is an insufficient number of school counselors altogether (1 counselor per 1500 students), who should mainly deal with children with special educational needs. It is worth mentioning that they try their integration into regular school environments, even if there are dramatic situations: teachers at regular classes do not have the special skills or training and they are not offered appropriate training sessions. In addition, counselors - also called itinerant teachers - cannot spend more than a few hours a week in such a class, in order to provide the necessary expertise.

Regarding public opinion, the common man either ignores the existence of counseling and the opportunity to appeal to them, or they associate counseling with mental illness (a phrase with significant negative meaning). Most people vehemently reject the idea to appeal to a counselor for a child's emotional problems (no one wants to know that he could have a child with a mental illness, a visit at the counselor is often associated with mental illness).

One of the many consequences of public attitudes toward counselors and counseling is the absence of counselors in schools and especially in the vocational guidance of children. In fact, according to the law, what matters in choosing the type of school attended after compulsory education (almost all parents opt for school) is a mix from several average grades: „Admission to the secondary or vocational school is done by the following procedure: a) where the number of candidates does not exceed the number of seats offered by the school, admission will be based on the student's educational portfolio, b) If the number of candidates is greater than the number of seats offered by the school, admission is done taking into account the proportion of $70 \%$ of the student's educational portfolio, the average grades at the graduation exam from compulsory education as well as the average grade from the national assessment and the average grade at the end of the 9th grade and $30 \%$ of the achieved grade during the admission exam at the respective school" (The Romanian Government, 2011).

As a reminiscence of communism, vocational schools were abolished and this reveals a paradox typical of this type of totalitarian society: although it is considered that work (especially physical work, the kind of work that involves direct interaction with matter or minimal interaction mediated by simple mechanical machines) makes us human and it is a prerequisite and compulsory assimilation of high values, no one wanted to work, so no one wanted his children to attend a vocational school, but a high school and later on go to a university. 


\section{Options dictated by random}

As a result, there is a career guidance program that takes account of students' personality characteristics as well as medium and long-term trends in the labor market, which is why the educational path of a student from Romania reveals glaring inadequacy: for example, graduates of high school focusing on mathematics and computer science (considered the best type of high school) with the option for the law school. This situation is described adequately (although it relates to the American education system) in (Bolles, 2007): „When we get out of school, or when we've been out of school for some time, and now are looking back, we realize there are three things a good education should have given us... but in our case did not. High school or college should have taught us: 1 . How to choose and find a job. A job that matches your gifts, skills, and experience. A job that not only puts bread on the table, clothes on your back, and shelter over your head, but also makes you happy ( p. 3).

Given this situation, during academic year 2013-2014 we applied a Holland questionnaire to first year students from the Faculty of Education Sciences (a total of 70 students) from the Petroleum-Gas University of Ploiești. The results are, as expected, surprising.

\section{Distribution of high schools in cities}

Distribution of respondents in large cities (two county capitals) and small towns, shows a higher proportion of candidates who have graduated from high schools in large cities (41 compared to 29), which would mean easier access to diversified sources of information. In fact, as mentioned, the circumstances are largely identical, since the presence of a school counsellor is signaled to one school and by a single respondent.

This leads us to advance two hypotheses: either the everyday presence of the digital infrastructure (internet, smart phone, tablet, laptop, etc.) clearly differentiates between small towns and big cities in terms of access to information, or the lack of interest in relation to high school graduates to their future career, disinterest of the formal and informal media that „block” search on their own in this area. However, our assumptions are contextual in relation to the fundamental reality of the absence of school counselling services in the Romanian education system.

\section{Distribution of respondents by types of schools}

Much more interesting is announced the distribution of respondents by types of schools. Bearing in mind the objectives of our study, we considered relevant high school grouping on the following three types: technical and technological high schools, philological and pedagogical high 
schools (suitable for those who intend to be university graduates in science education) - see Figure 1

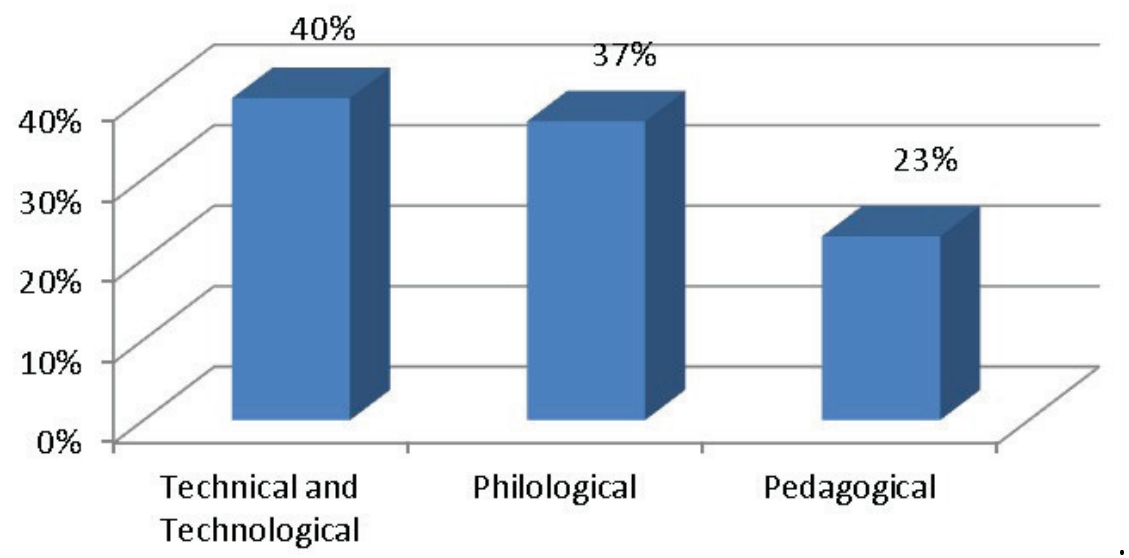

Fig. 1

In Romania there is currently one type of high school graduation exam - Baccalaureate - which allows a graduate to enroll in any academic specialization. Where appropriate, e.g. faculties of arts or education sciences, higher education institutions can organize aptitude tests which are eliminatory.

But beyond this bureaucracy, it is a significant presence that 28 respondents were graduates of technical and technological schools. However, it is worth noting the presence of the respondents coming from philological high schools with a relatively close cultural background to the profile of a student studying education sciences, but in fact attending such a faculty from the circumstantial reasons mentioned above (it is paradigmatic why they chose this specialization - the same students were freshmen three years ago; they gave one answer: because they loved children).

Why only 16 graduates of pedagogical high schools were enrolled in an education sciences college (that would have allowed them a natural continuation of studies begun in high school) since the two big cities from where we recruited the members of our sample approximately two hundred students annually graduate from pedagogical schools? Because many of them are turning to university studies focusing on philology, law, administration and economic sciences.

This is relevant for the confusion that reigns over the Romanian educational system, for children's attitudes influencing choices regarding the future studies and (possible) career, ultimately, for the indifference and inability of policy makers to reset priorities for the evolution of Romania's evolution on medium and long term. 


\section{Analysis of the data obtained by Holland test}

The „Holland Code” for every kind of personality, as we know, is made up of a combination of three of the six identified types: Realistic (R), Investigative (I), Artistic (A), Social (S), Entrepreneurial (E), and Conventional (C). For the teacher, the code is SAE, i.e. social, artistic and entrepreneurial.

If we assume that the primary personality type (in this case S) covers special technical skills, that are profession-specific, the following personality types (in our case A and E) cover mainly transfer skills.

It is clear that the personality of a professional (regardless of the field) is not split/ shared in such components or skills that he has. But we can say that the primary personality type (in our case, S) constitutes the core of a profession, although in different combinations of personality specific to other professions, and is what we (according to the specific literature) have called transfer skills.

If the primary type of personality is the tough core of the necessary skills for a profession, the associated types give individuality, the specific way in which an individual manifests himself in the field of that profession (his personality brand). From this point of view, it is quite difficult to determine which the characteristics of a successful teacher are because one impresses by consistency and rigor, while another by enthusiasm and involvement (among others, according to personality types associated by Holland typology).

In the description from (Jigau, 2006), a social personality type is a person ,who likes to work with people, in order to inform, advise, assist, train, educate, shape, care; has skills in using creative, nuanced language in this purposes" (p.38).

It appears that the teacher is the person who has powers regarding efficient social interactions, making homogeneous teams, developing an appropriate educational environment, developing project objectives and appropriate use of learning methods to arouse interest and, above all, motivate children.

Variations, as mentioned above, are introduced by the associated personality types, and in our case we find a large variety with a dominant artistic personality type - represented by 29 members of the sample. The artistic type is likely to have a rather ,affective-emotional approach to the world" (Jigau, 2006), in accordance with the way in which the child perceives the world at this age (p.37). In this sense in (Dewey, 1966) it's written: „Again, the child's life is an integral, a total one. He passes quickly and readily from one topic to another, as from one spot to another, but is not conscious of transition or break. There is no conscious isolation, hardly conscious distinction. The things that occupy him are held together by the 
unity of the personal and social interests which his life carries along. Whatever is uppermost in his mind constitutes to him, for the time being, the whole universe" (p. 6). Those members of the sample characterized by the business type (12 in number) may „,contaminate” children by energy, optimism and self-confidence. The conventional type, characteristic of 9 members of the sample, could attract conscientiousness, organization and practicality, while the investigative type brings to the fore the methodical, analytical spirit and contagious curiosity ( 7 members of the sample), etc.

The results of the Holland test - see Figure 2 - have led us to reexamine teaching strategies used in the preparation of future teachers also from this perspective.

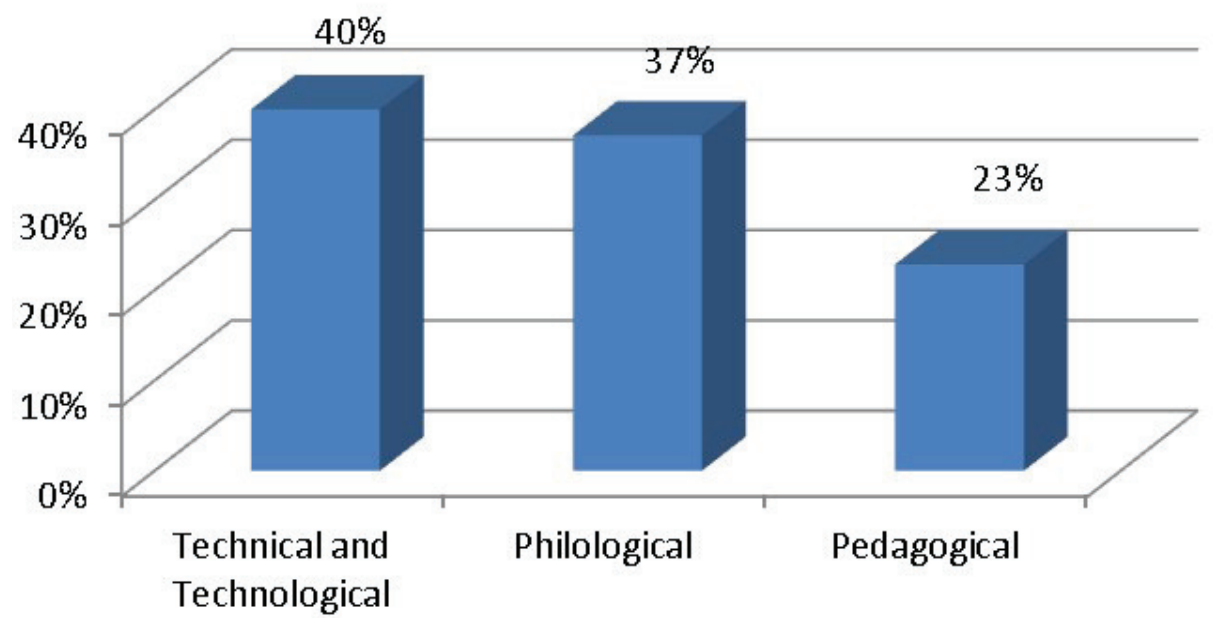

Fig. 2

If the primary type of personality should be seen as fundamental, and its features should be cultivated and refined through the curriculum, there are important characteristics of secondary and tertiary types because they allow us cultivation and refining of transfer skills, and these skills are those that are the teacher's style, and his ace. Since the university under scrutiny offers training programs for teachers, we decided to re-think the content as well as the instructional strategies used within them.

\section{What was lacking when making options}

Referring to one of his works, and the role of career guidance in general, Norman Amundson said (Amundson \& Poehnell, 1996): „,... you will learn to discover who you are and what you can do, how to make the right choices for your future careers/ jobs and how to make plans that will help you get and find the jobs that are available on today's changing labor market" (p. 5).

In this context, at the end of the first semester (three months had passed since the date of completion of the Holland test), we asked 
respondents to note those information, activities, etc. that would be useful to make a knowledgeable option regarding future university studies. Beyond reproach (which we consider reasonable) to teachers (considered solely responsible), we have drawn very useful suggestions for people / institutions interested in this issue:

- Schools should have a counselling center and a school counselor;

- Counsellors, using appropriate tools, should provide students with relevant information about their skills and interests;

- related to their own skills and interests, developing projects with academic institutions and companies that support them, in order to put students in direct contact with the occupational environment and those people with whom they could identify;

- Visits to universities and access to promotional materials that provide relevant information about their seriousness (credentials etc.), fields of study, study conditions (laboratories, libraries, etc.) and living conditions (campus cafeteria, club, sports, prices, etc.);

- Introduction of social studies in technical high schools;

- Visits of students from those universities who are interesting for pupils;

- finding out the reasons why one should choose a college or another, especially in the light of advantages and disadvantages of the career(s) for which one prepares (note that personal interests and skills are overshadowed, which is explained by the absence of school counselors);

- organizing volunteer activities to assist students in the process of becoming aware of employment opportunities and personal interests;

- Information on the dynamics of the labor market;

- Information on those sites where you can get reliable information about universities and the labor market;

- under what conditions (secondary school graduation, etc.) one could be admitted to a university without fees in previous years (state universities in Romania offer prospective students a number of places which are free of charge (publicly funded) and a number of places which are paid (the fee is paid by students), access to free of charge places is permitted only if certain criteria are met, (of which) one is the average grade for the Baccalaureate, while scholarships for the first semester of studies are given by following the same criteria;

- Talks between former high school students, currently students at those colleges that pupils are interested in (in this way, one would encourage the establishment of alumni associations in high schools);

- Educational fairs organized by universities;

- organizing lectures in universities, possibly with the participation of university professors and some students. 
It is worth noting that only one student considers relevant the information about the terms and conditions for obtaining a scholarship abroad, while no student considered relevant the information about the European labor market, although Romania has been a member of the European Union since 2007.

The first problem is that of the option for a particular school (say National College „Mihai Viteazul” from Ploiești), and then for a school profile, a conditional option in close connection with the procedure mentioned above on the one hand, and on the other hand, the number of secondary school graduates who, for one reason or another, choose the same school.

From the perspective of the university option, one may say that about half of the students who are part of our sample had to graduate from a high school they did not want, considering it unacceptable. The reasons why the kind of school was deemed unacceptable have no connection with dispositions, interests, their future plans, since at secondary level (first cycle of secondary education) there are almost no counselors, their number is quite limited, and their influence is meaningless on the basis of a quasi-generalized rejection of the idea of counseling on the one hand and, on the other hand, taking into account access procedures in high school.

Conversely, taking into account the school that the members of the target group have graduated from, we believe that the university option is groundless, even if there is justification for it. Thus, only students who come from one school (from a total of 14) refer to the existence of the school counselor, and out of these, only one student believes that the school counselor gave useful information regarding their choice of university (i.e., education science).

These data come from the responses of the sample members have offered to our request to note that information that would be needed to make an informed option about university (we mentioned the data earlier in this paper). Secondly, the conditions offered by universities in Romania are relatively similar, although the universities in the capital city (Bucharest, which is the largest cultural and economic center) offer more opportunities after graduation.

This advantage is offset by more expensive cost of living, meaning significantly higher costs for the future student, while European programs of scholarships for students (Leonardo, for example) tend to cancel this advantage, especially in those universities that have a counselling center and career guidance center that operate meaningfully. In line with the RAQAHE (Romanian Agency for Quality Assurance in Higher Education), every university that has such a center receives a certain number of points (i.e., the existence of such a center is not a must on the one hand, and on the other 
hand, what really counts is the formal existence of the center and not the volume and quality of activities).

The exaggerated tendency to centralize and unify curriculum almost entirely wiped out the differences between universities, those differences which resulted in the different schools of thought, with different questions and solutions (what we want to say is that the option for a university or another seems meaningless). It is this monochrome environment where high school graduates have to integrate in. For such graduates, career advice, own interests and values, dynamics and trends of the labor market are often empty words.

\section{Conclusions}

Beyond these re-settings of curricula, as far as the preparation of future teachers is concerned, the Holland test results have led us to develop a support program for high school students in the region of our university. We are aware that such a program would be necessary starting secondary school, but for now we do not have the resources to operate at this level and the program has the support and involvement of volunteer teachers and postgraduate students from the Faculty of Education Sciences:

- developing a website for high school pupils, that should be part of the University Counseling Centre. In this way, we could provide online resources to those interested: tools for self-knowledge and ways of using data, as well as data interpretation, information about universities, their credentials, the opportunities they provide (information will be provided by the universities, but will be monitored by our counselling center, because we want to provide a space for academic audiences), an online service for emergency situations, operating continuously and which requires the involvement of students making teams with students from the Master's program, information on institutions, regulations and trends of the (national and European) labor market etc.

- organization of joint teams (teachers and students, master students and students) to travel to schools in order to provide qualified support regarding career guidance (a kind of caravan that will have a set of tools that are appropriate to counseling and vocational guidance)

- organization of study visits of pupils interested in Petroleum-Gas University of Ploiești (and in other participating universities from our website) to attend certain courses, and organizing visits of professors to give lessons together with high school teachers in order to highlight the connection between the knowledge learned in school and university needs - Involvement of business people/ companies in the activities of the center - Organization of trainings on topics of career counselling with high school teachers and interested parents. 


\section{References}

Amundson, N., \& Poehnell, G. (1996). Career Paths. Richmond: BC: Ergon Communications.

Bolles, R. (2007). What Color Is Your Parachute? A Practical Manual for Job-Hunters and Career-Changers. Berkeley: Ten Speed Press.

Dewey, J. (1966). The Child and the Curriculum. Chicago, London: The University of Chicago Press.

Jigau, M. (2006). Consilierea carierei. Compendiu de metode şi tehnici.Bucuresti: Institutul de Stiinte ale Educatiei.

The Romanian Government. (2011, January 5). National Education Law. The Ofiicial Monitor of Romania, p. 1. 